Check for updates

Cite this: RSC Adv., 2017, 7, 29563

Received 19th May 2017

Accepted 22nd May 2017

DOI: $10.1039 / c 7 r a 05666 d$

rsc.li/rsc-advances

\section{Nanoarmoring: strategies for preparation of multi- catalytic enzyme polymer conjugates and enhancement of high temperature biocatalysis $\uparrow$}

\author{
Omkar V. Zore, ${ }^{\text {ab }}$ Paritosh Pande, ${ }^{a}$ Oghenenyerovwo Okifo, ${ }^{a}$ Ashis K. Basu, ${ }^{a}$ \\ Rajeswari M. Kasi ${ }^{\star a b}$ and Challa V. Kumar ${ }^{\star a b c}$
}

We report a general and modular approach for the synthesis of multi enzyme-polymer conjugates (MECs) consisting of five different enzymes of diverse isoelectric points and distinct catalytic properties conjugated within a single universal polymer scaffold. The five model enzymes chosen include glucose oxidase (GOx), acid phosphatase (AP), lactate dehydrogenase (LDH), horseradish peroxidase (HRP) and lipase (Lip). Poly(acrylic acid) (PAA) is used as the model synthetic polymer scaffold that will covalently conjugate and stabilize multiple enzymes concurrently. Parallel and sequential synthetic protocols are used to synthesise MECs, 5-P and 5-S, respectively. Also, five different single enzyme-PAA conjugates (SECs) including GOx-PAA, AP-PAA, LDH-PAA, HRP-PAA and Lip-PAA are synthesized. The composition, structure and morphology of MECs and SECs are confirmed by agarose gel electrophoresis, dynamic light scattering, circular dichroism spectroscopy and transmission electron microscopy. The bioreactor comprising MEC functions as a single biocatalyst can carry out at least five different or orthogonal catalytic reactions by virtue of the five stabilized enzymes, which has never been achieved to-date. Using activity assays relevant for each of the enzymes, for example AP, the specific activity of AP at room temperature and $7.4 \mathrm{pH}$ in $\mathrm{PB}$ is determined and set at $100 \%$. Interestingly, MECs 5-P and 5-S show specific activities of $1800 \%$ and $600 \%$, respectively, compared to $100 \%$ specific activity of AP at room temperature (RT). The catalytic efficiencies of $5-\mathrm{P}$ and $5-\mathrm{S}$ are $1.55 \times 10^{-3}$ and $1.68 \times 10^{-3}$, respectively, compared to $9.11 \times 10^{-5}$ for AP under similar RT conditions. Similarly, AP relevant catalytic activities of 5-P and 5-S at $65{ }^{\circ} \mathrm{C}$ show 100 and $300 \%$, respectively, relative to native AP activity at RT as the native AP is catalytically inactive at $65{ }^{\circ} \mathrm{C}$. The catalytic activity trends suggest: (1) MECs show enhanced catalytic activities compared to native enzymes under similar assay conditions and (2) $5-\mathrm{S}$ is better suited for high temperature biocatalysis, while both 5-S and 5-P are suitable for room temperature biocatalysis. Initial cytotoxicity results show that these MECs are non-lethal to human cells including human embryonic kidney [HEK] cells when treated with doses of $0.01 \mathrm{mg} \mathrm{mL}^{-1}$ for $72 \mathrm{~h}$. This cytotoxicity data is relevant for future biological applications.

\section{Introduction}

Here an easy, novel, modular and general method to synthesize highly catalytically active and stable multi (five) enzyme poly(acrylic acid) conjugates (MECs) is presented. PAA serves as a universal scaffold and is able to chemically conjugate several

\footnotetext{
${ }^{a}$ Department of Chemistry, University of Connecticut Storrs, CT 06269-3060, USA E-mail: challa.kumar@uconn.edu; kasi@ims.uconn.edu; Fax: +1-860-486-4745; Tel: +1-860-486-4713

${ }^{b}$ Institute of Materials Science, U-3136, University of Connecticut Storrs, CT 062693069, USA

${ }^{c}$ Department of Molecular and Cell Biology, University of Connecticut Storrs, CT 06269-3125, USA

$\dagger$ Electronic supplementary information (ESI) available: Supporting information file contains experimental details and supplemental data as noted in the text. See DOI: $10.1039 / \mathrm{c} 7 \mathrm{ra05666d}$
}

enzymes of varying isoelectric points. Comprehensive catalytic activities of MEC based bioreactor are investigated and compared to single enzyme-PAA conjugates and native or unmodified enzymes.

Nature utilizes a multi-enzyme catalytic complex, cellulosome, for efficient hydrolysis of cellulose. ${ }^{1}$ Using Nature as an inspiration, a major challenge is to design a bioreactor containing multiple enzymes that are covalently or chemically conjugated within a single universal scaffold. For industrially relevant applications, these multi enzyme conjugates are required to present stability, high catalytic activity, environmentally conscious features in cascade catalytic reactions or several orthogonal non-cascade catalytic reactions. ${ }^{2-5}$

Several examples of multiple enzymes physically adsorbed or encapsulated within a single scaffold are known. For instance, a set of three ${ }^{3}$ enzymes, comprised of glucose oxidase, lactate 
oxidase, and galactose oxidase, are non-covalently immobilized on an electrode using polyethylene glycol as a spacer and used for quantification of glucose, lactate, and galactose at millimolar concentrations. ${ }^{6}$ However, this immobilization strategy show leaching of enzymes from the electrode and displays a 20$25 \%$ reduction in catalytic activities. In another example, thirteen (13) different enzymes are physically adsorbed onto carbon nanotubes/carbon paper and used an enzymatic biofuel cascade reactor for sugar-based battery applications. While these nonimmobilized multi-enzymes present good activities at room temperature, the ability to function at higher temperature and long-term storage and usage are not addressed. ${ }^{7}$ Since catalytic activities are typically enhanced at higher temperatures, strategies to stabilize multiple enzymes for catalysis at temperatures higher than $25^{\circ} \mathrm{C}$ are beneficial. These limitations of enzymes can be overcome, at least in principle, by the covalent conjugation of enzymes with well-defined, suitably selected, synthetic polymers via facile but mild synthetic approaches. ${ }^{8}$ By combining proteins and polymers in a "synergistic" manner, new structures and unique materials can be designed, and properties of both components can be enhanced for specific applications. , $^{\mathbf{1 0}}$

Covalent or chemical conjugation of a single enzyme within a polymer or an inorganic support is well-understood. For example, using site-specific attachment strategies, single enzymes can be conjugated to end groups of polyethylene oxide. ${ }^{\mathbf{1 1 , 1 2}}$ These precisely defined single enzyme conjugates are used for biological applications. ${ }^{13}$ Single enzymes can also be randomly conjugated within polyacrylic acid (PAA) framework such that amino groups on the enzyme chemically react with carboxylic acid groups on PAA. ${ }^{\mathbf{1 4}, 15}$ Several such single enzyme conjugates are synthesized and display high stability and enhanced biocatalytic activities at higher temperatures and in organic solvents compared to native or unmodified enzymes. ${ }^{\mathbf{1 6}}$

There is only one known example of two different enzymes covalently conjugated to a single polymer support. ${ }^{8}$ Amine groups on GOx and HRP are covalently and randomly attached to carboxylic groups on PAA catalyzed by EDC resulting in GOxHRP-PAA bienzyme conjugates. These bienzyme conjugates present unprecedented catalytic activity and stability at $65{ }^{\circ} \mathrm{C}$ with little or no leaching of the active catalysts. Furthermore, PAA acts as a buffer and these enzymes are stabilized over $\mathrm{pH}$ of 2.5-7.4. While these reports suggest that PAA would be an excellent universal scaffold for conjugation of multiple enzymes, a general strategy for chemical covalent conjugation of several of different isoelectric points, amino groups and catalytic features within a universal polymer scaffold has not been achieved. The multiple enzyme polymer conjugate (MECs) platform will be very useful for cascade catalysis or in orthogonal single stream non-cascade chemical transformations.

In the present study, PAA is used a universal scaffold to covalent tether enzymes including glucose oxidase (GOx), horseradish peroxidase (HRP), lipase (Lip), acid phosphatase (AP) and lactate dehydrogenase (LDH) to form multi-catalytic enzyme complex (MEC). These five enzymes are chosen due to their widely different isoelectric points and surface availability of lysine groups (Table 1). These enzymes also used in several biocatalytic applications. For example, GOx and HRP catalyze redox transformations in sensing, catalysis, and waste-water remediation and they serve as cascade dyads. ${ }^{17-23}$ In contrast, LDH catalyzes dehydrogenation reactions for the production of enantiopure (-) lactate and 2-hydroxy acids that are precursors to many pharmaceutical drugs ${ }^{24,25}$ and for sensing of lactate. ${ }^{26}$ Hydrolases like AP are used widely for waste remediation, metal recovery, ${ }^{27}$ and determination of surfactants, ${ }^{28}$ whereas lipases are employed for the production of pharmaceutical drugs, cosmetics, leather, detergents, foods, perfumery, medical diagnostics and other synthetic materials. ${ }^{29-32}$ More importantly, LDH, GOx and HRP display significant reduction of catalytic activities at $50{ }^{\circ} \mathrm{C}$, while the activity of Lip and AP is rapidly decreases above $40{ }^{\circ} \mathrm{C}^{\mathbf{8 , 3 3 - 3 5}}$ Methods to stabilize these enzymes so that they can function at high temperatures are needed to enhance their catalytic activities and is a challenge that should be addressed.

Multiple enzyme-PAA conjugates (MECs) are synthesized using two different routes (Scheme 1). In Route 1, a parallel synthesis strategy is used: (step 1) Single enzyme-PAA conjugates are synthesized using GOx (yellow), HRP (green), AP (blue), LDH (black) and lipase (red) and PAA (brown string) to form GOx-PAA, HRP-PAA, AP-PAA, LDH-PAA and Lip-PAA, (step 2) these enzyme-PAA conjugates are mixed and crosslinked using 1-ethyl-3-(3-dimethylaminopropyl) carbodiimide (EDC) to form MECs (5-P, Scheme 1A). In Route 2, a sequential synthesis strategy of MEC is used: PAA and 5 enzymes are stirred together for 10-20 min and crosslinked using EDC to form MEC (5-S, Scheme 1B). The two MECs differ considerably in their

Table 1 Key properties of glucose oxidase (GOx), horseradish peroxidase (HRP), lactate dehydrogenase (LDH), acid phosphatase (AP) and lipase (Lip)

\begin{tabular}{|c|c|c|c|c|c|}
\hline & $\mathrm{GOx}^{8}$ & HRP $^{8}$ & $\mathrm{LDH}^{36}$ & $\mathbf{A P}^{37}$ & Lip $^{38}$ \\
\hline Enzymes & 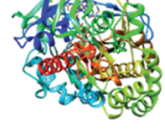 & $\begin{array}{l}32 \\
305\end{array}$ & 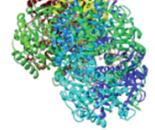 & 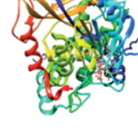 & \\
\hline Molecular weight $\left(\mathrm{g} \mathrm{mol}^{-1}\right)$ & 160000 & 40000 & 146400 & 45080 & 57100 \\
\hline pI & 4.6 & $3-9$ & 5.5 & $4.5-6.0$ & $4.3-4.7$ \\
\hline Number of Lys residues & 30 & 6 & 104 & 16 & 20 \\
\hline
\end{tabular}




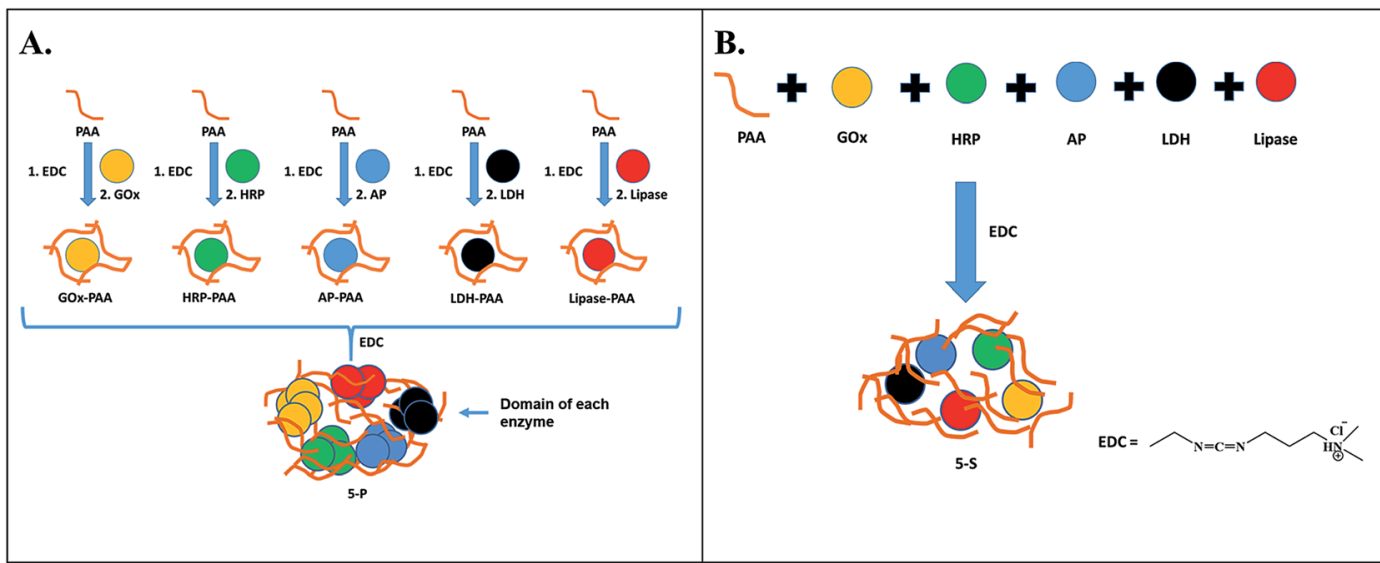

Scheme 1 Two different routes to synthesize MECs. In Route 1 (A), individual enzyme-PAA conjugates are synthesized using EDC chemistry, and then further crosslinked to prepare 5-P. In Route 2 (B), PAA and all 5 enzymes are mixed together and subsequently crosslinked using EDC to prepare 5-S. Here, GOx, HRP, AP, LDH and Lip are represented by yellow, green, blue, black and red circles, respectively, and PAA is shown as brown strings.

microenvironment due to fundamental differences in the synthesis protocols used and, therefore, it is critical to investigate their biocatalytic behaviors. Unprecedented stability and catalytic activities of these MECs at room temperature and at $65{ }^{\circ} \mathrm{C}$, compared to SECs and native unmodified enzymes under similar conditions, are reported.

\section{Experimental section}

\subsection{Materials}

$\operatorname{PAA}\left(M_{\mathrm{v}}=450000 \mathrm{~g} \mathrm{~mol}^{-1}\right.$ where $M_{\mathrm{v}}$ is viscosity average molecular weight), GOx (Aspergillus niger), lipase (Candida rugosa), hydrogen peroxide $\left(\mathrm{H}_{2} \mathrm{O}_{2}\right)$, glucose, $o$-methoxyphenol, EDC, NADH, sodium pyruvate, 4-nitrophenyl acetate, 4-nitrophenyl phosphate and uranyl acetate are purchased from Sigma-Aldrich (St. Louis, MO). HRP and LDH (Sus scrofa) are purchased from Calzyme Laboratories INC, San Luis Obispo, CA. AP (Triticum aestivum) is purchased from MP Biomedicals, Solon, $\mathrm{OH}$. Agarose is purchased from Molecular Biology Hoefer Inc., Allison, MA. All native enzymes are purified by dialysis. The HEK-293T cell line [ATCC CRL-11268] is purchased from ATCC (Mananas, VA).

\subsection{Synthesis of MECs}

MECs are synthesized using five different enzymes and PAA by two different synthesis routes, which include parallel (2-steps) and sequential synthesis (1-step). Key features of the five enzymes are displayed in Table 1.

2.2.1 Parallel synthesis of 5-P. MECs are synthesized using a two-step parallel process. In the step 1, individual enzyme-PAA conjugates are synthesized using EDC chemistry. First, a 2\% w/v stock solution of PAA is prepared by dissolving PAA in DI water and $\mathrm{pH}$ is adjusted to 7 . Second, $2.8 \mathrm{~mL}$ of the PAA solution is mixed with phosphate buffer, $10 \mathrm{mM}$, at $\mathrm{pH} 7.4$ and activated by EDC. Molar ratio of EDC to $-\mathrm{COOH}$ is maintained at $1.5: 1$. Third, the mixture is stirred for $20 \mathrm{~min}$ and then stock solution of GOx dissolved in PB is added dropwise such that molar ratio of enzyme : PAA is $1: 1$ and total solution volume is $10 \mathrm{~mL}$ and stirred for $6 \mathrm{~h}$. Finally, covalent conjugation is achieved through carboxyl groups on PAA and lysine amino groups on enzymes and GOx-PAA conjugates are prepared. In a similar manner the other four enzyme-PAA conjugates are synthesized. In step 2, five different enzyme-PAA conjugate are mixed with EDC and cross-linked. The EDC :-COOH ratio is maintained at $1.5: 1$.

2.2.2 Sequential synthesis of 5-S. Synthesis of MEC is carried out in one step. Here $5.6 \mathrm{~mL}$ of PAA stock solution and 5 enzymes are combined such that the molar ratio of total enzymes : PAA at $1: 1$ and stirred for $20 \mathrm{~min}$. These molar ratios are chosen based on literature reports. ${ }^{\mathbf{8}, 30}$ To this mixture, EDC is added such that the molar ratio of EDC : $-\mathrm{COOH}$ from PAA is $1.5: 1$ and the mixture is stirred for $20 \mathrm{~min}$. The sample is dialyzed using a $25 \mathrm{kDa}$ dialysis membrane in $\mathrm{pH} 7.4 \mathrm{~PB}$ to remove unreacted EDC and EDC-urea byproducts. As a control experiment, all five enzymes are mixed together in the absence of PAA, which resulted in a precipitate. Thus, conjugation with PAA is necessary to prevent aggregation and precipitation of the five enzymes. Further experimental details on characterization of MECs by zeta potential, agarose gel electrophoresis, circular dichroism, transmission electron microscopy, dynamic light scattering as well as catalytic activity measurements and kinetics studies is presented in the ESI. $\dagger$

\section{Results}

In this study, a general and modular method by which GOx, HRP, AP, LDH and Lip are conjugated to PAA by parallel and sequential strategies to form MECs, is presented. In the parallel synthetic method, individual enzyme-PAA conjugates are first synthesized (GOx-PAA, HRP-PAA, Lip-PAA, AP-PAA, and LDHPAA) and then these enzyme-PAA conjugates are further treated with EDC to produce MEC, 5-P. In the sequential synthesis route, all 5 enzymes and PAA are mixed together in specific ratios and then crosslinked covalently with EDC to form MEC, 5-S. 


\subsection{Synthesis of MECs}

3.1.1 Synthesis of 5-P. The MEC, 5-P, is synthesized in two steps. In step 1, single enzyme-PAA conjugates are synthesized. For example, PAA is activated using EDC and GOx is then added dropwise to form covalently conjugated GOx-PAA. Molar ratios of EDC :-COOH and total enzyme : PAA are maintained at $1.5: 1$ and $1: 1$, respectively. Random covalent conjugation between PAA and GOx is achieved by reaction through - $\mathrm{COOH}$ groups on PAA and lysine $\mathrm{NH}_{2}$ groups on GOx. The conjugation reaction is carried out for $6 \mathrm{~h}$ followed by dialysis using $25 \mathrm{kDa}$ dialysis membrane in $\mathrm{pH} 7.4 \mathrm{~PB}$ for 3 cycles of $5 \mathrm{~h}$ each. Final concentration of GOx in the GOx-PAA conjugate is $12.5 \mu \mathrm{M}$. Other enzyme-PAA conjugates including HRP-PAA, AP-PAA, Lip-PAA and LDH-PAA are similarly synthesized and purified by dialysis. In step 2, GOx-PAA, HRP-PAA, AP-PAA, Lip-PAA and LDH-PAA are mixed in equimolar amounts and stirred for $20 \mathrm{~min}$. Then, EDC is added such that molar ratio of EDC :$\mathrm{COOH}$ is $1.5: 1$. After $6 \mathrm{~h}$, the samples are purified by dialysis to remove unreacted EDC and EDC-urea. Final concentration of each enzyme in $5-\mathrm{P}$ is $6.5 \mu \mathrm{M}$.

3.1.2 Synthesis of 5-S. Sequential synthesis of MEC is carried out in one step. All 5 enzymes including GOx, HRP, $\mathrm{LDH}$, Lip and AP in equimolar amounts and PAA are mixed together in a specific molar ratio such that total enzyme : PAA concentration was $1: 1$ and stirred for $20 \mathrm{~min}$. Chemical conjugation is initiated by the addition of EDC and multi enzyme conjugate, 5-S is synthesized. Final concentration of each enzyme in the 5 -S is $6.5 \mu \mathrm{M}$, similar to 5 -P. Successful synthesis of enzyme-PAA, 5-P and 5-S was confirmed using agarose gel electrophoresis, zeta potential, and TEM.

\subsection{Agarose gel electrophoresis}

Successful conjugation of enzymes to PAA and formation of MECs is confirmed by agarose gel electrophoresis studies at $\mathrm{pH}$ 7.4 in $40 \mathrm{mM}$ Tris acetate buffer. In Fig. 1A, lanes 1-7 are loaded with Lip, GOx, LDH, AP, HRP, 5-P and 5-S, respectively. Agarose gel data for single enzyme-PAA conjugates is shown in Fig. S1, ESI. $\dagger$ Electrophoretic mobility of enzymes and enzymeconjugates will depend on the charge and the molecular weight. Native enzymes GOx, AP, Lip and LDH move towards the
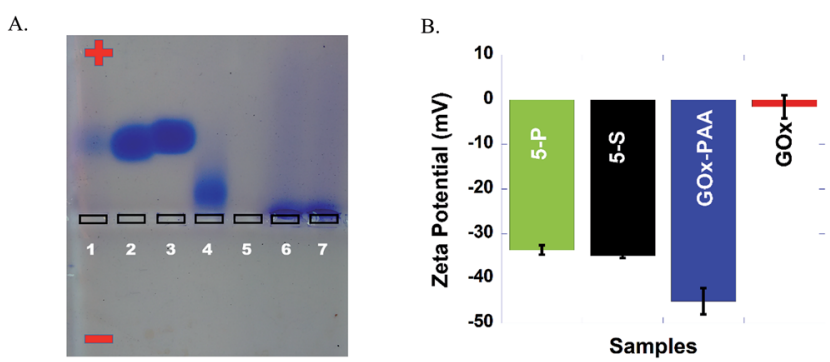

Fig. 1 (A) Agarose gel image of enzymes (lipase, GOx, LDH, AP and HRP), 5-P, and 5-S loaded in lanes 1-7, respectively. Electrophoresis is performed in $40 \mathrm{mM}$ Tris acetate at $\mathrm{pH}$ 7.4. (B) Zeta potentials of 5-P (green), 5-S (black), GOx-PAA (blue), and GOx (red), performed at $25^{\circ} \mathrm{C}$ in $10 \mathrm{mM}$ PB at $\mathrm{pH} 7.4$. positive electrode due to the net negative charge on these enzymes. ${ }^{36}$ The staining of HRP in the gel is very poor and its electrophoretic properties could not be established. The MECs will have high molecular weight and may remain in the loading well without any movement through the gel. The absence of any other bands pertinent to free enzymes and single enzyme-PAA conjugates in 5-S and 5-P under electrophoresis confirms formation of MECs using PAA as a scaffold.

\subsection{Zeta potential studies}

The charge and the electrophoretic mobility of the conjugates and native enzymes at $\mathrm{pH}$ 7.4 $\mathrm{PB}$ are established using zeta potential measurements. When enzymes conjugate with PAA to form either single enzyme-PAA conjugates or MECs, the net negative charge on these samples increase relative to unmodified enzymes due to the presence of unreacted $\mathrm{COOH}$ in PAA. The zeta potential of GOx and GOx-PAA, 5-P, and 5-S is determined to be $-1.50 \mathrm{mV},-45.0,-33.5$ and $-35.0 \mathrm{mV}$, respectively, Fig. 1B. Similarly, HRP, AP, Lip, and LDH show zeta potentials of $-2.00,-5.22,-14.0$ and $-20.0 \mathrm{mV}$, respectively, Fig. S2 ESI. $\dagger$ As expected, the potentials decrease considerably in enzyme-PAA conjugates. HRP-PAA, AP-PAA, Lip-PAA, and LDH-PAA show zeta potentials of $-46.5,-42.5,-44.0$ and $-40.0 \mathrm{mV}$, respectively, Fig. S2 ESI. $\dagger$

\subsection{Transmission electron microscopy (TEM)}

Morphologies of MECs, single enzyme-PAA and unmodified native enzymes are analyzed using TEM. Samples 5-P, 5-S, and GOx are imaged using Tecnai T20 TEM. Samples 5-P and 5-S showed extensive crosslinked nanogels whereas GOx (C) showed aggregated particles, Fig. 2(A-C). The free enzyme when drop cast tend to aggregate and precipitate easily. The nano gel morphology of GOx-PAA has been previously reported. ${ }^{8}$

\subsection{Dynamic light scattering (DLS)}

The hydrodynamic radii of MECs, enzyme-PAA, and native enzymes are determined by DLS. All samples are diluted using pH 7 PB such that the enzyme concentration in each DLS experiment is maintained at $0.5 \mathrm{nM}$. The enzymes GOx, HRP, AP, Lip, and LDH show hydrodynamic radii of 6.02, 1.84, 9.10, 1.49 and $3.44 \mathrm{~nm}$, respectively. The hydrodynamic radius of GOx-PAA, HRP-PAA, AP-PAA, Lip-PA and LDH-PAA are determined to be $22.3,26.8,32.6,16.7$ and $16.6 \mathrm{~nm}$, respectively. The MECs, 5-P and 5-S, show structures of 80-100 nm, possibly due to the random nature of conjugation and incorporation of different sized enzymes, Table S1 and Fig. S3 in ESI. $\dagger$

\subsection{Circular dichroism (CD) studies}

The secondary structure of enzymes before and after conjugation with PAA in $\mathrm{pH}$ 7.4 PB at room temperature is established using far UV circular dichroism (CD) studies. Due to the physical strain imposed on the enzyme upon PAA chemical conjugation, enzyme-PAA conjugates are expected to present reduced molar ellipticities compared to unmodified native enzymes. 
A.

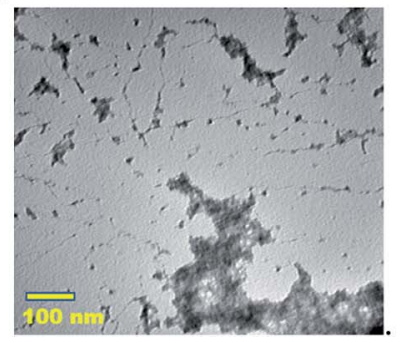

B.

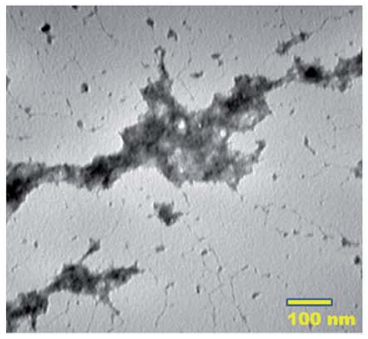

C.

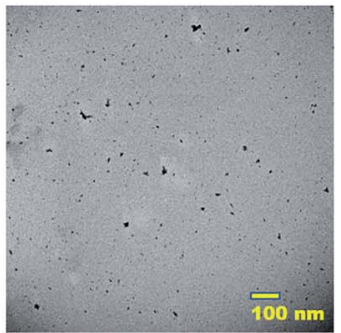

Fig. 2 Transmission electron micrographs (A) 5-P, (B) 5-S and (C) GOx. Samples are diluted using pH 7.4 PB such that equivalent protein concentration is $5-10 \mathrm{nM}$ and stained using $0.5 \mathrm{wt} \%$ uranyl acetate and imaged.

The CD spectra of GOx, GOx-PAA (A); LDH, LDH-PAA (B) and 5-P, 5-S (C) is shown in Fig. 3. The inset in panel A \& B shows the relative \% ellipticity retention of enzyme-PAA and corresponding unmodified enzyme. To calculate relative \% ellipticity retention, signal intensity of samples at $222 \mathrm{~nm}$ is used. The signal intensity at that wavelength for unmodified enzyme is set at $100 \%$ and accordingly the relative intensity of enzyme-PAA is calculated. The CD spectra and relative \% ellipticity retention of AP, AP-PAA (A), HRP, HRP-PAA (B) and Lip, Lip-PAA (C) are presented in Fig. S4, ESI. $\uparrow$ To calculate the relative $\%$ ellipticity, retention signal intensity at lowest position in $\mathrm{CD}$ spectra, which is $222 \mathrm{~nm}$ for GOx, LDH, and AP and $208 \mathrm{~nm}$ for Lip and HRP. Relative \% ellipticity retention of the enzymes within the single-enzyme PAA showed reduction in retention of secondary structures compared to unmodified enzyme. GOx-PAA, LDHPAA, AP-PAA, HRP-PAA, and Lip-PAA show reduction in \% relative ellipticity retention of $89,71,68,66$, and $4 \%$, respectively, relative to the native enzymes' ellipticity of $100 \%$.

\subsection{Activity studies}

Catalytic activities of SECs and MECs are carried out at room temperature using enzyme specific substrates, assays and experimental conditions. Enzymes including GOx, HRP, AP, LDH, and Lip use glucose, o-methoxyphenol, 4-nitrophenyl phosphate, NADH, and 4-nitrophenyl acetate, respectively, as substrates to estimate catalytic features. Detailed catalytic assays are presented in the ESI. $\dagger$ Relative \% specific activity of each enzyme conjugate is calculated by fixing the initial rate of its corresponding unmodified enzyme as $100 \%$ at room temperature.

3.7.1 Activity studies at room temperature. The $3 \mathrm{D}$ hierarchical structure of the enzyme or enzyme in conjugates determines its catalytic activities. The 3D structure retention of enzymes within single enzyme-PAA conjugates is easily established by far UV-CD experiments. However, the far UV-CD profile for MECs is complicated due to overlapping signatures of each enzyme and is difficult to deconvolute and decode \% structure retention of each enzyme. Therefore, catalytic activity specific to each enzyme within MEC is used as an indirect measurement of its structure retention at room temperature. Fig. 4 shows the relative \% specific activities for GOx (A) and AP (B) and the same for HRP, LDH, and Lip is presented in Fig. S6 in ESI. $\dagger$ All \% specific activities of GOx containing samples are calculated based on the initial rate of GOx at room temperature at $\mathrm{pH} 7.4, \mathrm{~PB}$ as $100 \%$. For example, GOx-PAA, 5-P, and 5-S showed activities of 80,78 , and $91 \%$, respectively, relative to the activities of native GOx at room temperature and $\mathrm{pH} 7.4$ assigned as $100 \%$. In another case, using AP based assays, AP showed large increase in \% specific activity, where AP-PAA, 5-P, and 5-S showed activity of 626,1940 , and $970 \%$, respectively, based on initial rate of native AP at room temperature and $\mathrm{pH}$ 7.4 assigned as $100 \%$.
A.

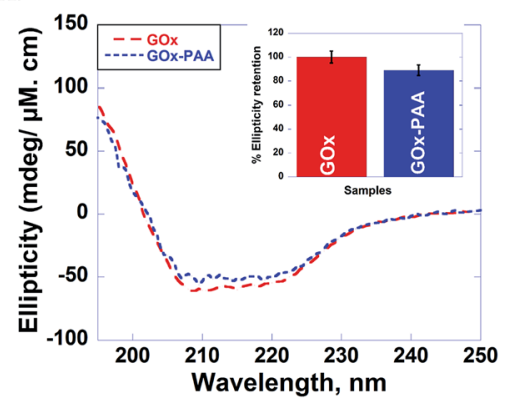

B.

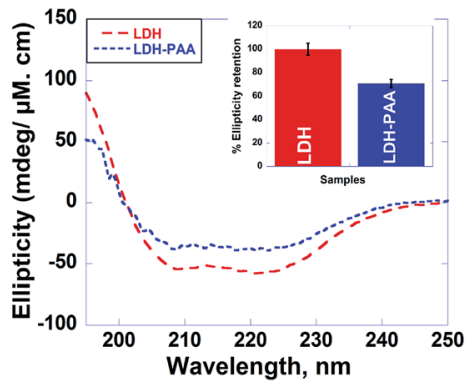

C.

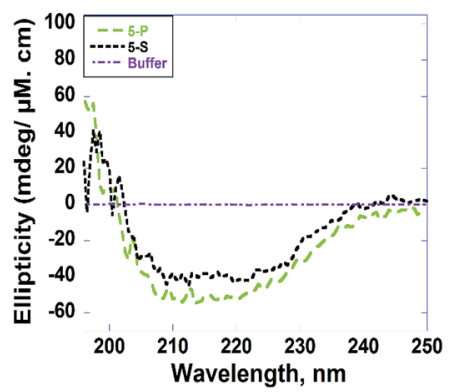

Fig. 3 Circular dichroism (CD) spectra of (A) GOx (red), GOx-PAA (blue), (B) LDH (red), LDH-PAA (blue) and (C) 5-P (green), 5-S (black). CD spectra are monitored from $190-250 \mathrm{~nm}$ in $\mathrm{pH} 7.4 \mathrm{~PB}$ at room temperature $\left(25^{\circ} \mathrm{C}\right)$. The inset in panel (A \& B) shows the relative ellipticity retention, when peak at $222 \mathrm{~nm}$ for unmodified enzyme is set at $100 \%$, against which the relative signal intensity of enzyme-PAA is compared. Relative ellipticity retention for MECs, where there are five enzymes, could not be computed as the CD spectrum cannot be deconvoluted due to overlapping signatures. 
A.

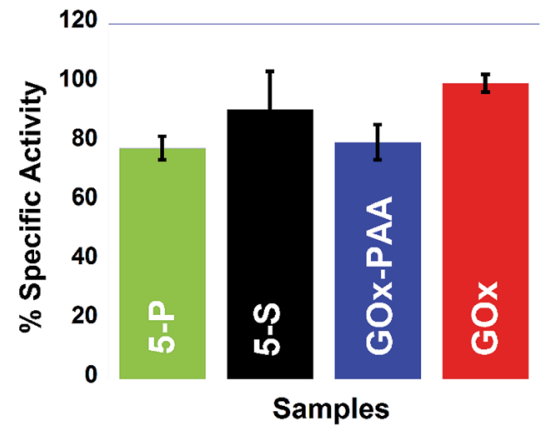

B.

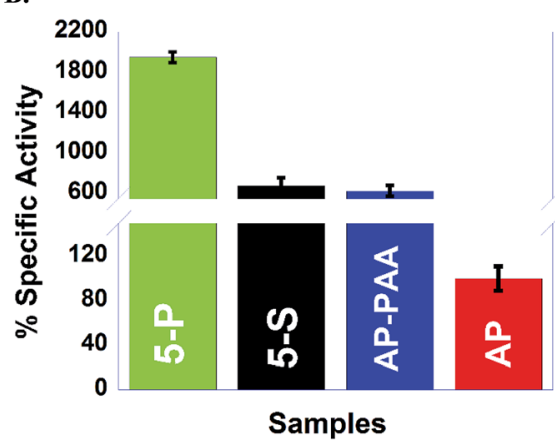

Fig. 4 Percentage specific activities o GOx containing samples (A) and AP containing samples (B) are presented: 5-P and 5-S are shown in green and black, respectively. GOx, GOx-PAA, AP and AP-PAA are shown in red, blue, red, and blue respectively. Catalytic activities are established at $25^{\circ} \mathrm{C}$ in $\mathrm{pH} 7.4,10 \mathrm{mM}$ PB for GOx and AP containing samples. Relative specific activity on the $Y$ axis is with respect to the initial rate of free enzyme (GOx or AP) at $25^{\circ} \mathrm{C}$ as $100 \%$.

Similar trends are obtained in the case of Lip, where LipPAA, 5-P, and 5-S show activities of 114,89 , and $450 \%$, respectively, relative to the native enzyme at room temperature and $\mathrm{pH}$ 7.4 PB. This unprecedented increase in activity of AP and Lip conjugates may be due to increase accessibility of the catalytic active site to the substrate. In general, the synthetic approach to stabilize AP and Lip with PAA, improved activities of AP in conjugates by 18 -fold and activities of Lip in conjugates by 4.5 fold at room temperature relative to the native enzymes at room temperature and pH 7.4 Tris. However, in contrast, HRP and LDH present within single enzyme-PAA and MECs show decrease in catalytic activities relative to the native enzymes at room temperature and $\mathrm{pH} 7.4 \mathrm{~PB}$ and $\mathrm{pH} 8$ Tris, respectively. For HRP conjugates, HRP-PAA, 5-P, and 5-S show activities of 60,49 , and $54 \%$, respectively, whereas $\mathrm{LDH}$ conjugates, LDHPAA, 5-P, and 5-S showed activities of 38,57 , and $40 \%$, respectively, assuming that the native enzymes show $100 \%$ activity at room temperature and $\mathrm{pH} 8$ Tris. The \% specific activities of Lip, HRP and LDH are shown in Fig. S6 in ESI $\dagger$ and Table 2.

3.7.2 Activity studies at $65{ }^{\circ} \mathrm{C}$. The catalytic activities of 5-S, 5 -P, and other samples are explored at $65{ }^{\circ} \mathrm{C}$ using similar methods as described in Experimental sections. The single enzyme conjugates, MECs and native enzymes are incubated in a cuvette and the temperature is maintained at $65{ }^{\circ} \mathrm{C}$, the substrate specific to each enzyme assay is added to the cuvette and the product formation is monitored. The percentage specific activities for each enzyme at $65{ }^{\circ} \mathrm{C}$ and $\mathrm{pH} 7.4 \mathrm{~PB}$ is presented relative to the percentage activity of native enzyme at room temperature and $\mathrm{pH} 7.4 \mathrm{~PB}$ which is set as $100 \%$. Fig. 5 shows the \% specific activity plots for GOx and AP samples. Plots for other enzymes including HRP, LDH and Lip are in Fig. S7 in ESI† and Table 3.

Catalytic activity studies at $65{ }^{\circ} \mathrm{C}$ and $\mathrm{pH}$ 7.4 PB are established for MECs and single enzyme conjugates. For example, while 5-P, 5-S, and GOx-PAA showed 132, 112, and 136\% activity (Fig. 5A), native GOx exhibited complete deactivation. In each case, the percentage specific activity of the conjugate at $65{ }^{\circ} \mathrm{C}$ is relative to $100 \%$ activity for the corresponding native enzyme at room temperature and pH 7.4 PB. Similarly, 5-P, 5-S, and AP-
PAA present 103, 298, and 106\% activity (Fig. 5B), whereas unmodified AP is deactivated and unmodified AP presents $100 \%$ activity at room temperature and $\mathrm{pH}$ 7.4 PB. Biochemical assays at $65{ }^{\circ} \mathrm{C}$ for Lip, HRP, and LDH show that 5-S present enhanced catalytic activities compare to 5-P. These trends in catalysis may be due to microenvironment in MECs produced due to the synthetic strategy and may allow the substrate better access to active sites in 5-S compared to 5-P leading to enhanced activities in 5-S. Additionally, in 5-S, domains of similar enzymes may not form easily due to the synthetic strategy. However, cooperative effects from dissimilar enzymes may further enhance overall activities in these MECs.

The effect of the polymer scaffolding and the microenvironment of the enzymes in 5-S, 5-P, enzyme-PAA on enzymatic rate constants is evaluated using Lineweaver-Burk plots. Kinetic constants including $K_{\mathrm{M}}, V_{\max }$, catalytic efficiency and $K_{\text {cat }}$, are extracted and compared to the native enzymes. The data are presented below.

Table 2 Relative specific activity (\%) of Lip, HRP, and LDH containing samples at pH 7.4 in 10 mM PB (Lip and HRP) and pH 8 in 10 mM Tris buffer (LDH), at $25{ }^{\circ} \mathrm{C}$ with activities of free (native, pristine or unmodified) enzymes referenced at 100\%

\begin{tabular}{ll}
\hline Samples & $\%$ specific activity \\
\hline
\end{tabular}

Lip enzymatic assay

5-P

89

5-S

450

Lip-PAA

114

HRP enzymatic assay

$5-\mathrm{P}$

49

5-S

54

HRP-PAA

60

$\begin{array}{ll}\text { LDH enzymatic assay } & \\ 5-\mathrm{P} & 57 \\ 5-\mathrm{S} & 40\end{array}$

LDH-PAA $\quad 38$ 
A

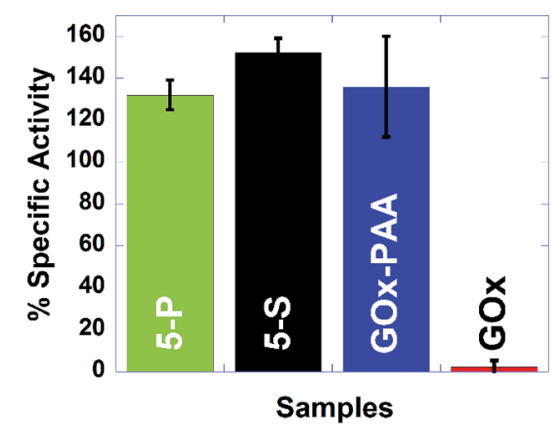

B

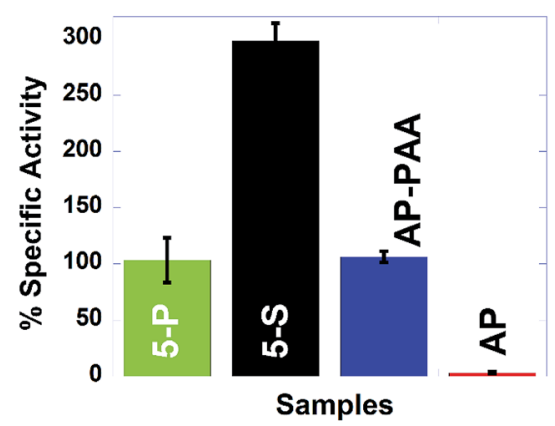

Fig. 5 High temperature $\left(65^{\circ} \mathrm{C}\right)$ activities in $\mathrm{pH} 7.4,10 \mathrm{mM} \mathrm{PB}$ for GOx and AP containing samples, (A) and (B), respectively. \% specific activity is plotted on the $Y$ axis, using the initial rate of free enzyme at $25^{\circ} \mathrm{C}$ as $100 \%$ since free enzyme at $65^{\circ} \mathrm{C}$ did not present any catalytic activity. 5 -P, 5 $\mathrm{S}$ are shown in green and black, respectively. GOx, GOx-PAA, AP and AP-PAA are shown in red, blue, red, and blue, respectively.

Table 3 Specific activities (\%) of Lip, HRP, and LDH containing samples at pH 7.4 in $10 \mathrm{mM} \mathrm{PB} \mathrm{(Lip,} \mathrm{HRP)} \mathrm{and} \mathrm{pH} 8$ in $10 \mathrm{mM}$ Tris buffer (LDH)/ Tris buffer at $65{ }^{\circ} \mathrm{C}$ relative to free enzyme activities set at $100 \%$ at room temperature $\left(25^{\circ} \mathrm{C}\right)$

\begin{tabular}{ll}
\hline Samples & $\%$ specific activity $\left(65^{\circ} \mathrm{C}\right)$ \\
\hline Lip enzymatic assay & \\
5-P & 0 \\
5-S & 540 \\
Lip-PAA & 78 \\
Lip & 0 \\
& \\
HRP enzymatic assay & \\
5-P & 98 \\
5-S & 138 \\
HRP-PAA & 149 \\
HRP & 47 \\
LDH enzymatic assay & \\
5-P & \\
5-S & 0 \\
LDH-PAA & 77 \\
LDH & 146 \\
\end{tabular}

\subsection{Kinetic studies}

3.8.1 $\boldsymbol{K}_{\mathbf{M}}$ and $\boldsymbol{V}_{\mathbf{m a x}}$. The enzymatic activities depend on the rates of several steps in the catalytic cycle, and insights into these steps is gained by determining the Michaelis constant $\left(K_{\mathrm{M}}\right)$ and the maximum initial velocity $\left(V_{\max }\right)$. Using the initial rates determined with increasing substrate concentrations, Lineweaver-Burk plots (plot of inverse initial rate $v s$. inverse substrate concentration) and Michaelis-Menten plots are constructed using the equation

$$
1 / V=K_{\mathrm{M}} / V_{\max }[\mathrm{S}]+1 / V_{\max }
$$

where $[\mathrm{S}]$ is the substrate concentration, $V$ is the initial reaction rate, $K_{\mathrm{M}}$ is the Michaelis constant, and $V_{\max }$ is the maximum initial velocity. Lower $K_{\mathrm{M}}$ values indicate increased affinity of the substrate for the enzyme active site. Another important kinetic parameters include: (1) $K_{\text {cat }}$ or the turnover number, which is the number of moles of substrate molecules converted to the product molecules per unit time and (2) $K_{\text {cat }} / K_{\mathrm{M}}$, which is the catalytic efficiency. The highest catalytic efficiency is the most desired. Lineweaver-Burk plots ${ }^{37}$ of GOx and AP containing samples are shown in Fig. 6 and that of HRP, LDH and Lip are provided in Fig. S8 in ESI. $\dagger$ All of these analyses are performed at room temperature in $\mathrm{pH}$ 7.4 $\mathrm{PB}$ (HRP, Lip) and $\mathrm{pH} 8$ Tris ( $\mathrm{LDH})$. The kinetic parameters of all the samples using 5 different enzymatic assays are tabulated in Table S2 in ESI. $\dagger$ According to Fig. 6A and Table S1, $\uparrow$ 5-P, 5-S, GOx-PAA, and GOx show $K_{\mathrm{M}}$ values of $5.93,1.98,0.844$, and $5.17 \mathrm{mM}$, respectively, and catalytic efficiencies of $0.050,0.064,0.096$ and 0.103 , respectively. GOx show highest value of $K_{\text {cat }}$ of $0.533 \mathrm{~s}^{-1}$ and GOx-PAA show lowest value of $K_{\text {cat }}$ of $0.081 \mathrm{~s}^{-1}$. Kinetic parameters of GOx are computed based on cascade enzymatic reaction of GOx and HRP (ESI, † Section 1.8). The parameters are controlled by the enzyme(s) in the cascade system with lower stability and shorter half-life. While these parameters are not optimized, half-lives of the less stable enzyme may be improved by adjusting the relative loadings of the enzyme. For example, if GOx is assumed to have reduced half-life as compared to that of HRP, it can be loaded in excess amount so that the bienzyme GOx/HRP will have the desired activity for the desired length of time.

Lineweaver-Burk plots for HRP containing samples at room temperature and $\mathrm{pH} 7.4 \mathrm{~PB}$ are designed and $K_{\mathrm{M}}$ values for 5-P, 5-S, HRP-PAA, and HRP are calculated to be 0.796, 0.330, 0.461, and $0.107 \mathrm{mM}$, respectively (Fig. S8A and Table S2 $\dagger$ ). Reduced catalytic efficiency for 5-P and 5-S are noted, 0.155 and 0.097, respectively, whereas HRP-PAA and HRP showed similar catalytic efficiency of 0.308 and 0.318 , respectively. In the case of $K_{\text {cat }}, 5-P$ and HRP-PAA showed similar values of 0.123 and 0.142 $\mathrm{s}^{-1}$, respectively, while, 5 -S and HRP presented values of value of 0.032 and $0.034 \mathrm{~s}^{-1}$, respectively.

Kinetic parameters AP containing samples at room temperature and $\mathrm{pH}$ 7.4 PB are established (Fig. 6 and Table $\mathrm{S} 2 \dagger$ ). $K_{\mathrm{M}}$ values of 5-P, 5-S, AP-PAA, and AP are, 12.9, 6.55, 43.0 and $21.9 \mathrm{mM}$, respectively. However, 5-P and 5-S showed highest $K_{\text {cat }}$ and catalytic efficiency values. For example, $K_{\text {cat }}$ values of 5-P and 5 -S are 0.020 and $0.011 \mathrm{~s}^{-1}$, respectively, and catalytic 
A.

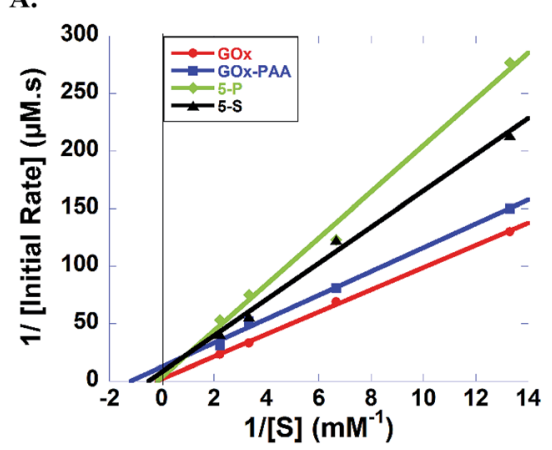

B.

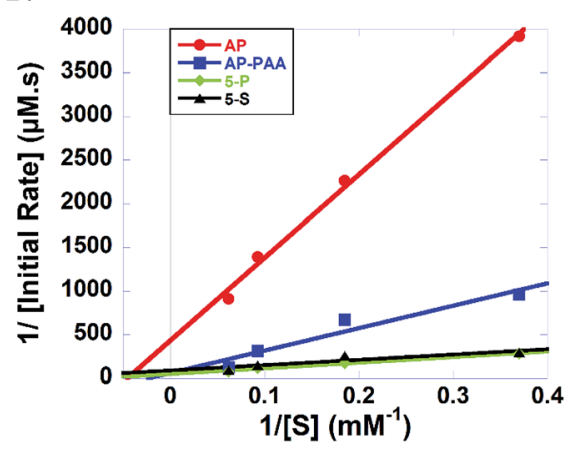

Fig. 6 (A) Lineweaver-Burk plots of GOx (red), GOx-PAA (blue), 5-P (green) and 5-S (black) with increasing glucose (0.075-0.45 mM). (B) Lineweaver-Burk plots of AP (red), AP-PAA (blue), 5-P (green), and 5-S (black) with increasing 4-nitrophenylphosphate (2.7-16.2 mM). All the enzyme concentrations, native and within conjugates, are 1 micromolar. Studies are carried out in $\mathrm{pH} 7.4,10 \mathrm{mM} \mathrm{PB}$ at $25{ }^{\circ} \mathrm{C}$.

efficiency values are $1.55 \times 10^{-3}$ and $1.68 \times 10^{-3}$, respectively. $K_{\text {cat }}$ value for AP-PAA is $0.020 \mathrm{~s}^{-1}$ and catalytic efficiency is 3.96 $\times 10^{-4}$. In agreement with room temperature catalytic activity trends, AP shows the lowest $K_{\text {cat }}$ and catalytic efficiency of 0.002 $\mathrm{s}^{-1}$ and $9.11 \times 10^{-5}$, respectively.

Similarly, Lineweaver-Burk plots for LDH containing enzymes are used to derive the kinetic parameters at room temperature in $\mathrm{pH} 8$ Tris (Fig. S8B and Table S2 $\uparrow$ ). $K_{\mathrm{M}}$ values for 5-P, 5-S, LDH-PAA, and LDH are, 0.196, 0.196, 0.073, and $0.198 \mathrm{mM}$, respectively and catalytic efficiencies are 0.036 , $0.031,0.096$, and 0.364 , respectively. Turn over number or $K_{\text {cat }}$ values for 5-P, 5-S, and LDH-PAA are similar and show values of $0.007,0.006$, and $0.007 \mathrm{~s}^{-1}$, respectively, whereas, LDH exhibits highest $K_{\text {cat }}$ of $0.072 \mathrm{~s}^{-1}$.

Lineweaver-Burk plots for Lip are shown in Fig. S8C and Table S1. $\dagger$ Accordingly, $K_{\mathrm{M}}$ values of 5-P, 5-S, Lip-PAA, and Lip are $0.133,0.070,0.122$, and $0.372 \mathrm{mM}$, respectively, and catalytic efficiencies are $0.007,0.014,0.016$, and 0.013 , respectively. 5-P, 5 -S, and Lip-PAA exhibited similar $K_{\text {cat }}$ values of $0.001,0.001$, and 0.002 , respectively, whereas Lip exhibited highest turnover number $\left(K_{\text {cat }}\right)$ of $0.005 \mathrm{~s}^{-1}$.

\subsection{Cellular toxicity of MECs and enzyme-PAAs in HEK-293T cells}

The in vitro compatibility of the enzyme-PAA conjugates with HEK-293T cells up to $16 \mathrm{~h}$ of co-incubation period is monitored by measuring the intracellular dehydrogenase activity, for 5-P (Fig. 7A) and GOx-PAA (Fig. 7B), which is a reliable measure for quantifying the intracellular metabolism in a mammalian cell line. ${ }^{38,39}$ Optimal intracellular dehydrogenase concentration is essential for efficient metabolism in the human cells. The reduction in dehydrogenase concentration, which is a quantitative measure of reduced intracellular metabolism, confirmed the reduction in cellular activity and eventually, the cell death. The cell viability is also examined by evaluating their extracellular morphology using phase contrast microscopy, a universal benchmark for assessing the overall physiological health of a cell, ${ }^{40}$ for 5-P (Fig. 7C), GOx-PAA (Fig. 7D) and Lip-PAA (Fig. 7E). It is evident that cells incubated with $1.2 \mu \mathrm{M}$ Lip-PAA showed normal morphology (Fig. 7E), whereas cells incubated with 5-P and GOx-PAA at low nanomolar and picomolar levels, respectively, showed stressed cell morphology as seen in Fig. 7C and D. Fig. S9 in ESI $\dagger$ shows the changes in intracellular metabolism as the dose of Lip-PAA is varied from 0-1.2 $\mu \mathrm{M}$. Similar behavior is noted for AP-PAA, HRP-PAA and LDH-PAA (data not shown).

Except for the conjugates that contained GOx, no other conjugate showed any difference in intracellular metabolism or extracellular morphology relative to control cells even at the highest co-incubation dose (1.2 $\mu \mathrm{M}$, Fig. 7D). Similar behavior is

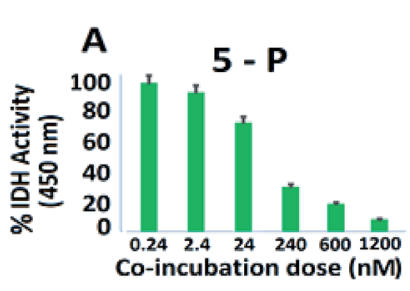

C

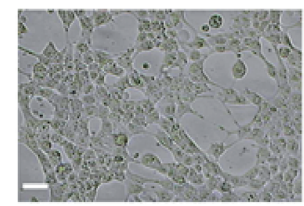

E

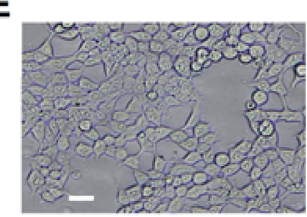

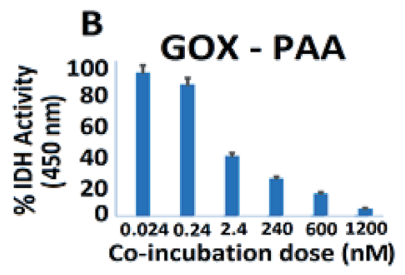

D

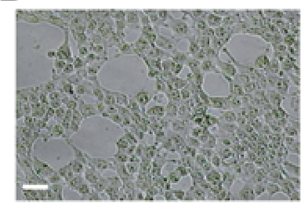

$\mathbf{F}$

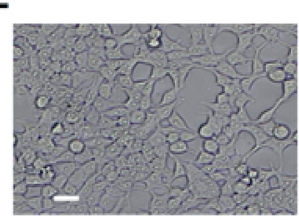

Fig. 7 Dose-dependent in vitro cytotoxicity of GOx containing conjugates as a function of intracellular dehydrogenase (IDH) activity of HEK-293T cells. The plot clearly indicates the lack of cytotoxicity at low nanomolar level for 5-P (A) and picomolar level for GOx-PAA (B). Other enzyme-PAAs showed no drop in intracellular metabolism even at the highest administered dose of $1.2 \mu \mathrm{M}$. (C-E) shows morphology of HEK-293T cells co-incubated with $240 \mathrm{nM}$ of 5-P (C), $2.4 \mathrm{nM}$ of GOx-PAA (D), $1.2 \mu \mathrm{M}$ of lipase-PAA (E), and control HEK-293T cells (F). Scale bar: $10 \mu \mathrm{m}$. 
observed for the conjugates containing GOx, such as 5-P, 5-S, and GOx-PAA at low nanomolar dose (2-20 nM). In sum, the toxicity results obtained by monitoring intracellular dehydrogenase activity and light microscopy demonstrated that most enzyme-polyacrylic acid conjugates are highly biocompatible.

\section{Discussion}

A general and modular strategy to synthesize novel, synthetic multi-enzyme polymer chemical conjugates using different enzymes and PAA as the polymer scaffold is presented here. This strategy is developed based on the polymer's ability to conjugate one or two enzymes and protect the enzymes from stressors including temperature, aggregation and proteases as shown in previous publication..$^{\mathbf{8 , 3 0 , 3 2 , 4 4}}$ The novelty of this work arises due to the use of PAA scaffold, to conjugate multiple enzymes of varying isoelectric points, $\mathrm{pH}$ profiles, physical properties and catalytic properties. We also wish to investigate the temperature stability of MECs not only at room temperature but also at $65{ }^{\circ} \mathrm{C}$ compared to unmodified native enzymes. The catalytic properties presented by MECs cannot be realized from a mixture of physical mixtures of multiple enzymes, which aggregate and precipitate and lose all catalytic activity.

Two distinct synthetic strategies, the parallel and sequential synthesis, are tested here. In parallel synthesis, in the first step enzyme-PAA conjugates are made via the classical covalently crosslinking of lysine amino $\left(\mathrm{NH}_{2}\right)$ groups from the enzyme with carboxyl $(-\mathrm{COOH})$ groups of PAA. In the second step, these individual enzyme-PAA conjugates are mixed together and further conjugated to form 5-P MEC. In the sequential one-step one-pot synthesis, all 5 enzymes and PAA are mixed together, without any visible precipitation, and crosslinked to form 5-S MEC. More importantly, microenvironments of the enzymes in 5-P and 5-S are expected to be different. In 5-P inter-penetrating domains of similar enzyme-PAA conjugates may be formed due to the synthetic protocol, while in 5-S domains of similar enzyme-PAA conjugates may not be easily attained as these are pre-mixed before crosslinking. This difference in microenvironment of 5-P and 5-S will result in very different catalytic behaviors, and this concept has never been examined before. Furthermore, the single pot strategy to covalently immobilize five different enzymes within PAA can be easily extended to thirteen or more enzymes of different pIs useful for cascade reactions including sugar to energy applications.

Successful syntheses of 5-P, 5-S, and single enzyme-PAA conjugates are confirmed using agarose gel electrophoresis, TEM, DLS, and zeta potential studies. Agarose gel electrophoresis studies are based on the size and charge of the samples. The MECs carry more negative charge due to carboxyl groups from PAA and they are larger in size compared to individual enzymes (Fig. 1A). Increased negative charge should propel the MECs towards positive electrode of the gel but the increased size of the MECs can hamper its movement. As shown in Fig. 1A, due to increase in size, the MECs were stuck in the well of the agarose gel with some streaking (lane 6 and 7). Agarose gel of the immobilized enzymes conjugated with PAA (MEC 1 and 2) indicated that all the enzymes are covalently conjugated to the polymer and hardly any unreacted enzymes or single enzyme conjugates are present in the gels. However, it is hard to estimate the concentration of the enzymes in the MECs due to their overlapping UV signatures. The concentration of the individual enzyme in the MEC is calculated based on amount of enzyme used in the synthesis protocol and quantitative crosslinking of each enzyme is expected.

TEM micrographs clearly show nanogel morphologies of 5-P and 5-S similar to reported single enzyme-PAA conjugates, Fig. 2A and B, whereas the native enzyme, GOx for example, showed discreet aggregated particles. Due to the polyvalence of the PAA as well as the proteins, chemical crosslinking of these units can result in conjugates of a distribution of sizes. The distribution and the average size of the crosslinked conjugates depends on the polymer concentration, protein concentration, EDC concentration as well as the reaction time. For example, when dilute solutions are used, smaller aggregates are expected but when high concentrations are used these smaller aggregates may undergo further cross linking and produce larger aggregates. Here reaction conditions are carefully optimized to obtain nanogels of 80-100 $\mathrm{nm}$. In contrast GOx solution is drop cast onto TEM grids. During the drying process and during imaging, water is removed and GOx will form small aggregates as noted from TEM.

Zeta potential data confirms increase in negative charge after chemical conjugation with PAA, and this trend is consistent among all chemical conjugates (Fig. $1 \mathrm{~B}$ and $\mathrm{S} 1 \dagger$ ). The average hydrodynamic radius of the MECs is determined characterized by DLS (Table S1, ESI $\dagger$ ). Both 5-P and 5-S show increase in hydrodynamic size compared to individual enzyme-PAA conjugates as well as the free enzymes. These results are in agreement with the mobility pattern of the conjugates observed by agarose gel electrophoresis.

Retention of secondary structure of MECs is important for biocatalytic activity, which is established using $\mathrm{CD}$ and compared to CD spectra of free enzymes and enzyme-PAA conjugates. The CD spectra of the conjugates are compared with those of the unconjugated enzymes or native enzymes (Fig. 3 and also Fig. S2 and S4 $\dagger$ ). Except in the case of Lip-PAA, the spectra are reasonably similar in intensity as well as peak positions, but not identical. Thus, some structural changes do occur upon conjugation with the polymer. Severe loss in intensity in the case of Lip-PAA is likely due to aggregation but the Lip-PAA conjugate is nearly as active as the free enzyme. Thus, this loss in CD signal cannot be directly attributed to complete loss in enzyme secondary structure.

The secondary structure of each enzyme within 5-P and 5-S could not be compared with the single enzyme conjugates or native enzymes due to difficulty in resolving and deconvoluting the spectra of each enzyme in the MECs. The spectral shapes of 5-P and 5-S are comparable to the single enzyme-PAA conjugates, which may indicate at least partial retention of secondary structure. In the absence of concrete structural retention data from UV and CD studies, enzymatic activities of 5-P and 5-S are investigated and compared with single enzyme-PAA conjugates and free enzymes and is an indirect form of structural retention investigation. 
The catalytic activity of one enzyme in the presence of other enzymes within MECs and the effect of method of MEC synthesis (parallel vs. sequential addition) have never been explored before. The interpenetrating domains of a single enzyme-PAA conjugates within the 5-P MEC and the domains in 5-S MEC where the enzymes are mixed together and then conjugated (Scheme 1) could impact enzyme conformational states. The polymer scaffold may also sequester or expel the substrate and play an active role in the catalysis, as demonstrated before. ${ }^{\mathbf{1 1}}$

Catalytic activities are determined at room temperature at pH 7.4 PB are established using five different enzymatic assays where each assay is designed to interrogate one of the five enzymes in the MECs. For example, with GOx based assays, 5-P and 5-S show activities similar to GOx-PAA and GOx at room temperature and $\mathrm{pH} 7.4 \mathrm{~PB}$. In contrast, for HRP and $\mathrm{LDH}$ based assays, $\sim 50 \%$ loss in activity is noticed for 5-P and 5-S when compared to pristine enzymes at room temperature and pH 7.4 PB. In another example, enzymatic assays for AP show unprecedented increase in activity for 5-P, 5-S and AP-PAA relative to native AP. However, enzymatic assays for Lip showed moderate increase in catalytic activity for 5-S and Lip-PAA relative to native Lip at room temperature and $\mathrm{pH} 7.4 \mathrm{~PB}$. These improvements in catalytic activities of AP and Lip conjugates may be attributed to the exposure of the active sites to the substrate. ${ }^{\mathbf{4 2 , 4 3}}$ Contribution of volumetric changes to the catalytic activity profile after conjugation to polymer in single and multi-enzyme fashion is minimal due to the excessive volume of the buffer used during catalysis. The total volume of PAA and all enzymes is small when compared to the volume of the buffer.

To test the robustness of these MECs, activity studies are performed at $65{ }^{\circ} \mathrm{C}$ at $\mathrm{pH} 7.4 \mathrm{~PB}$. MECs and enzyme-PAA conjugates present improved stability and activity retention compared to the native unmodified enzyme. For example, GOx activity assay indicates more than $100 \%$ activity retention for 5 $\mathrm{P}, 5$-S and GOx-PAA at $65{ }^{\circ} \mathrm{C}$ at $\mathrm{pH} 7.4 \mathrm{~PB}$ compared to GOx activity at room temperature and $\mathrm{pH}$ of $7.4 \mathrm{~PB} \%$ since free enzyme at $65{ }^{\circ} \mathrm{C}$ did not present any catalytic activity. Similar observations are noted for AP and HRP activity assays where 5-P, 5-S, AP-PAA, and HRP-PAA $65{ }^{\circ} \mathrm{C}$ at $\mathrm{pH} 7.4 \mathrm{~PB}$ retain more than $100 \%$ of the activity relative to the activity of the unconjugated/ free enzyme at room temperature and $\mathrm{pH} 7.4 \mathrm{~PB}$. Both native enzymes AP and HRP present negligible activity at $65{ }^{\circ} \mathrm{C}$. The activity of 5-S in the case of AP and HRP activity assay increase to 300 and $200 \%$, respectively, at $65{ }^{\circ} \mathrm{C}$ compared to native enzymes at room temperature. Increase in these activities is only observed for 5-S but not for 5-P. The domain formation in the case of 5-P seems to be an impediment for augmentation of activity at $65{ }^{\circ} \mathrm{C}$. However, domain formation did not negatively impact the activity of 5-P in the case of GOx, AP, or HRP based catalytic assays.

In the case of LDH and Lip activity assays, 5-P did not show any activity at $65{ }^{\circ} \mathrm{C}$ and $\mathrm{pH} 8$ Tris and $\mathrm{pH} 7.4 \mathrm{~PB}$, respectively. However, 5-S in the case of $\mathrm{LDH}$ and Lip activity assay showed $77 \%$ and $540 \%$ of activity, which is significantly better compared than 5-P. The microenvironment in 5-S is different from 5-P and could significantly impact observed difference in catalytic activities for $\mathrm{LDH}$ and Lip based assays at $65{ }^{\circ} \mathrm{C}$ and $\mathrm{pH}$ 7.4 PB. Thus 5-S may be exploited for high temperature catalytic applications as it is easier to synthesize, more robust and catalytic more active at $65{ }^{\circ} \mathrm{C}$ compared to $5-\mathrm{P}$.

To further understand the activity enhancement at room temperature and $\mathrm{pH}$ 7.4 $\mathrm{PB}$ (GOx, HRP, AP and Lip) and $\mathrm{pH} 8$ Tris (LDH), enzyme kinetics are carried out and systematic changes in $K_{\mathrm{M}}, V_{\max }, K_{\text {cat }}$, and catalytic efficiencies of 5-P, 5-S, single enzyme-PAA conjugates and native unmodified enzymes are obtained using Lineweaver-Burk plots. For example, in GOx containing samples, $K_{\mathrm{M}}$ values of GOx-PAA and 5-S are low compared to $K_{\mathrm{M}}$ values of unmodified GOx. In contrast, 5-P shows slightly higher $K_{\mathrm{M}}$ compared to GOx. Enzyme samples with lower $K_{\mathrm{M}}$ have higher affinity for the substrate. However, lower $K_{\mathrm{M}}$ values observed for some of the conjugates may partly explain the retention or enhancement of activity at $65{ }^{\circ} \mathrm{C}$ compared to native GOx, which loses its catalytic activity completely at $65^{\circ} \mathrm{C}$. In another example, huge enhancement of activity using AP activity assay for AP-PAA, 5-P, and 5-S can be explained based on $K_{\mathrm{M}}$ and catalytic efficiency. At room temperature and $\mathrm{pH}$ 7.4 PB, AP-PAA and 5-S had 6 times higher activity and 5-P had 20 times higher activity compared to AP. These correlate well with the catalytic efficiencies of these samples. Also, 5-S and 5-P show higher substrate affinity as their $K_{\mathrm{M}}$ values are lower than that of AP at room temperature. These nanogel type enzyme conjugates may pre-concentrate the substrate around the enzyme, which directly enhances substrate affinity and reaction rate. ${ }^{28}$

Reduction in activity of LDH and HRP containing samples after polymer conjugation and formation of MECs can be explained via changes in $K_{\mathrm{M}}$ and catalytic efficiency. Catalytic efficiency decreases in the case of HRP-PAA, 5-P, and 5-S to $0.308,0.155$, and 0.097 from 0.318 of HRP, which directly relates to the reduction in activity of $\mathrm{HRP}(100 \%)$ to (45-60\%) for HRPPAA, 5-P, and 5-S. A similar trend is noted in the case of LDH containing enzyme conjugates. Catalytic efficiency decreases from 0.364 in $\mathrm{LDH}$ to $0.03-0.09$ in the case of LDH-PAA, 5-P, and 5-S. Similarly, activity retention of $\mathrm{LDH}-\mathrm{PAA}, 5-\mathrm{P}$, and 5-S is reduced by $40-60 \%$ when compared to $\mathrm{LDH}$.

Lip containing samples showed an increase in catalytic efficiencies after polymer conjugation, for example, Lip-PAA and 5-S while 5-P showed a decrease. Catalytic efficiency of Lip (0.013) is increased for Lip-PAA (0.016) and 5-S (0.014), indicating $114 \%$ and $450 \%$ increase in activity of Lip-PAA and 5-S, respectively. Structure of the lipase active site and its conformation are known to regulate its activity. ${ }^{31}$ If the enzyme is trapped in its active state during the conjugation, then it is likely that the conjugate will be more active and vice versa. Similarly, the decrease in activity of 5-P (89\%) is related to its decrease in catalytic efficiency $(0.007)$ where the enzyme is locked into a less active confirmation. ${ }^{31}$

There are several examples of multi-enzyme systems that are physically adsorbed or physically encapsulated within a support, which showed enhancement or retention in catalytic activity in cascade or non-cascade catalysis. ${ }^{47-54}$ While, recyclability of these physically encapsulated system has been optimized and these enzymes can last a few cycles, their catalytic 
performance at higher temperatures has not been investigated. Catalytic activity is typically enhanced at higher temperatures and strategies to stabilize multiple enzymes at different temperatures are beneficial. In sharp contrast, 5-S and 5-P show significant activity retention or even catalytic activity enhancement in non-cascade or orthogonal biocatalysis at room temperature and at $65{ }^{\circ} \mathrm{C}$ compared to native enzymes at room temperature and $\mathrm{pH}$ 7.4 PB. Our previous work has shown that chemical confinement of the single enzyme and bi-enzymes by PAA will reduce the overall conformational entropy of the system and results in structure retention while improving thermal stability and catalytic performance at higher temperatures. ${ }^{8}$ But However, optimization of crosslink densities, molecular weight of PAA, and concentration of enzymes need to be investigated to recycle these enzyme conjugates. Here recyclability studies of MECs are not evaluated but methods to optimize recyclability of these MECs will be investigated in the near future.

To extend the use of these MECs for implantable bioreactor applications in animals, bio-toxicities are tested. The toxicity of enzyme-polyacrylic acid conjugates on HEK-293T cells is evaluated for four to forty-eight hours by quantifying the intracellular dehydrogenase activity and monitoring the cell morphology using phase-contrast optical microscopy. The results show no toxic effects of enzyme-PAA conjugates in HEK$293 \mathrm{~T}$ cells up to $1.2 \mu \mathrm{M}$ dose except for GOx containing samples like GOx-PAA, 5-P, and 5-S, which show toxicity at low nanomolar levels and MECs (5-P and 5-S) which showed toxicity at low picomolar levels. The toxicity of GOx containing samples can be attributed to the glucose oxidase mediated conversion of D-glucose $\left(4.5 \mathrm{~g} \mathrm{~L}^{-1}\right)$ present in the cell culture media into $\mathrm{H}_{2} \mathrm{O}_{2}$ and D-glucose-1,5-lactone which gets further hydrolyzed to Dgluconic acid. The catalytic generation of $\mathrm{H}_{2} \mathrm{O}_{2}$ and gluconic acid significantly lowers the $\mathrm{pH}$ of cell culture media from its normal physiological range ( $\mathrm{pH}$ 7.4-7.6, blood red) to the acidic range ( $\mathrm{pH}$ 6.0-6.8, yellow) resulting in metabolic acidosis in HEK-293 cells. Due to the excellent stability of enzyme-PAA conjugates, the GOx containing PAA-conjugates and MECs are able to completely overwhelm the intrinsic bicarbonate buffer system present in the cell culture media. This, in turn, resulted in an acidic environment adversely affecting the cell survivability.

To our knowledge, this is the first study that reports the biocompatibility of enzyme-PAA and MECs in a wellestablished human cell line for 48 hours. Our results strongly indicate that not only these complexes are highly stable in the complex biological growth medium, but also they are non-toxic. These conjugates, therefore, may be considered for implantable devices.

\section{Conclusions}

This is the first report in which 5 enzymes with different pI values and catalytic properties are stabilized using functional polymer to form multi-catalytic enzyme complexes (MECs) using two distinct strategies. This is a general and modular strategy that can be extended to many enzymes as most enzymes contain amino groups that can covalently conjugate with hydrophilic PAA, which serves as a universal scaffold. In the parallel synthesis protocol (5-P), individual enzyme-PAA complexes are synthesized first and these were further crosslinked by EDC chemistry. In sequential method of synthesis (5S), all 5 enzymes are mixed with PAA and then crosslinked using EDC. In 5-S, the enzyme structures are locked-in by the polymer shroud before exposing to other enzyme-polymer conjugates while in 5-P, each enzyme has the potential to interact with other enzymes as well as PAA during the conjugation. Thus, in 5-P microdomains of each-enzyme polymer networks are formed which are interpenetrated during the second step. In 5$\mathrm{S}$, these microdomains are less likely to form, unless certain enzymes aggregate individually or in the presence of specific partners, aggregation/precipitation is absent, and hence, enzymes in 5-S may be more homogeneously dispersed. These MECs are used for room and high temperature catalysis. Room temperature activity studies showed that MEC formation enhanced the AP and Lip activities of 5-P and 5-S by 5-20 folds when compared to the activities of corresponding unmodified enzymes. In contrast, MEC formation had no effect on GOx activity of 5-P and 5-S. At high temperature, all unmodified enzymes nearly lost all their activities, except HRP. In contrast, 5-P and 5-S showed 1 to 3 fold increase in activity for AP, GOx and HRP, whereas LDH and Lip showed peculiar behavior where 5-P completely lost activity and 5-S retained $70 \%$ in the case of LDH and $540 \%$ activity in the case of Lip. In principle, the enzymatic activities are tunable by controlling the affinity of the substrates to the polymer scaffolding surrounding the enzymes, which can promote substrate binding by increasing the local concentrations of the substrates near the enzyme. In the case of cellulosome, the cellulose-binding domain enhances the catalytic activities by increasing the affinity of the multicatalytic complex with cellulose. Our studies are only preliminary in this context, but they point to possibilities for tuning the enzymatic activities by controlling the synthesis method and composition of the MECs in a rational manner. The general method of making robust, active, artificial multi-catalytic complexes of multiple enzymes of different pI values opens up new avenues for high temperature catalysis and low-toxicity biocatalysts for implantable biofuel cells.

\section{Acknowledgements}

C. V. K acknowledges NSF EAGER grant (DMR-1441879) for financial support of the work. C. V. K and R. M. K thank the University of Connecticut Research Foundation, Research Excellence Program Award 2015. This research was also partially funded by NIEHS grant ES023350 to AKB.

\section{References}

1 C. M. Fontes and H. J. Gilbert, Annu. Rev. Biochem., 2010, 79, 655-681.

2 P. A. Santacoloma, G. Sin, K. V. Gernaey and J. M. Woodley, Org. Process Res. Dev., 2011, 15, 203-212. 
3 Bio Based Economy, http://www.bio-economy.net/ applications/applications_enzymes.html, accessed February 25, 2016.

4 N. Gurung, S. Ray, S. Bose and V. Rai, BioMed Res. Int., 2013, 2013, 1-18.

5 S. Li, X. Yang, S. Yang, M. Zhu and X. Wang, Comput. Struct. Biotechnol. J., 2012, 2, 1-10.

6 W. J. Sung and Y. H. Bae, Sens. Actuators, B, 2006, 114, 164169.

7 Z. Zhu, T. K. Tam, F. Sun, C. You and Y. H. P. Zhang, Nat. Commun., 2014, 5, 1-8.

8 H. Klok, J. Polym. Sci., Part A: Polym. Chem., 2005, 43, 1-17.

9 C. Boyer, X. Huang, M. R. Whittaker, V. Bulmus and T. P. Davis, Soft Matter, 2010, 7, 1599-1614.

10 K. Heredia and H. D. Maynard, Org. Biomol. Chem., 2007, 5, 45-53.

11 A. Abuchowski, T. Van Es, N. Palczuk and F. Davis, J. Biol. Chem., 1977, 252, 3578-3581.

12 D. Bontempo, K. L. Heredia, B. A. Fish and H. D. Maynard, J. Am. Chem. Soc., 2004, 126, 15372-15373.

13 F. Veronese and G. Pasut, Drug Discovery Today, 2005, 10, 1451-1458.

14 V. Thilakarathne, V. A Briand, R. M. Kasi and C. V. Kumar, Langmuir, 2011, 27, 7663-7671.

15 V. Mudhivarthi, K. Cole, M. Novak, K. Westley, I. Deshapriya, Y. Zhou, R. M. Kasi and C. V. Kumar, J. Mater. Chem., 2012, 22, 20423-20433.

16 O. Zore, P. J. Lenehan, C. V. Kumar and R. M. Kasi, Langmuir, 2014, 30, 5176-5184.

17 O. V. Zore, A. Pattammattel, S. Gnanaguru, C. V. Kumar and R. M. Kasi, ACS Catal., 2015, 5, 4979-4988.

18 X. Cao, Y. Li, Z. Zhang, J. Yu, J. Qian and S. Liu, Analyst, 2012, 137, 5785-5791.

19 A. Heller and B. Feldman, Chem. Rev., 2008, 108, 2482-2505.

20 C. Huber, M. Preis, P. J. Harvey, S. Grosse, T. Letzel and P. Schroder, Chemosphere, 2016, 146, 435-441.

21 J. Gong, C. S. Lee, E. J. Kim, Y. Y. Chang and Y. S. Chang, J. Hazard. Mater., 2016, 310, 135-142.

22 Y. Zhang, Y. Yong, J. Ge and Z. Liu, ACS Catal., 2016, 6, 37893795.

23 X. Ji, Z. Su, P. Wang, G. Ma and S. Zhang, ACS Catal., 2014, 4, 4548-4559.

24 N. G. Karaguler, R. B. Sessions and B. Binay, Biochem. Soc. Trans., 2007, 35, 1610-1615.

25 M. J. Kim and G. M. Whitesides, J. Am. Chem. Soc., 1988, 110, 2959-2964.

26 A. Chaubey, M. Gerard, R. Singhal, V. S. Singh and B. D. Malhotra, Electrochim. Acta, 2001, 46, 723-729.

27 M. Claire, Bacterial acid phosphatase and its application to waste remediation and metal recovery, $\mathrm{PhD}$ thesis, University of Birmingham, UK, 2011.

28 H. Tanaka, Y. Horiuchi and K. Konishi, Anal. Biochem., 1975, 66, 489-497.

29 N. N. Gandhi, Applications of Lipase, J. Am. Oil Chem. Soc., 1997, 74, 621-634.
30 C. J. Gray, J. S. Narang and S. A. Barker, Enzyme Microb. Technol., 1990, 12, 800-807.

31 S. Negishi, S. Shirasawa, Y. Arai, J. Suzuki and S. Mukataka, Enzyme Microb. Technol., 2003, 32, 66-70.

32 R. Fernandez-Lafuente, J. Mol. Catal. B: Enzym., 2010, 62, 197-212.

33 J. Huang, Y. Huang, X. Wu, W. Du, X. Yu and X. Hu, Parasitol. Res., 2009, 104, 287-293.

34 L. Nguyen, T. Dao, T. Zivkovic, M. Fehrholz, W. Schaefer and S. Salomon, Enzyme Microb. Technol., 2010, 46, 479-486.

35 G. Q. Zhang, Q. J. Chen, J. Sun, H. X. Wang and C. H. Han, J. Basic Microbiol., 2013, 53, 868-875.

36 G. Terlecki, E. Czapinska and K. Hotowy, Cell Mol. Biol. Lett., 2007, 12, 378-395.

37 T. Akiyama, H. Uchimiya and H. Suzuki, Plant Cell Physiol., 1981, 22, 1023-1028.

38 Y. C. Liou, A. G. Marangoni and R. Y. Yada, Food Res. Int., 1998, 31, 243-248.

39 A. Ghimire, O. V. Zore, V. K. Thilakarathne, V. A. Briand, P. J. Lenehan, Y. Lei, R. M. Kasi and C. V. Kumar, Sensors, 2015, 15, 23868-23885.

40 O. V. Zore, P. J. Lenehan, C. V. Kumar and R. M. Kasi, Langmuir, 2014, 30, 5176-5184.

41 Y. Liu, Y. Luo, J. Wu, Y. Wang, X. Yang, R. Yang, B. Wang, J. Yang and N. Zhang, Sci. Rep., 2013, 3, 1-8.

42 A. P. Pattammattel, C. L. Williams, P. Pande, A. K. Basu and C. V. Kumar, RSC Adv., 2015, 5, 59364.

43 B. Ekwall, V. Silano, A. Paganuzzi-Stammati and F. Zucco, Toxicity tests with mammalian cells, in Short-term Toxicity Tests for Non-genotoxic Effects, ed. P. B., John Wiley and Sons Ltd., 1990, ch. 7.

44 C. M. Riccardi, K. S. Cole, K. R. Benson, J. R. Ward, K. M. Bassett, Y. Zhang, O. V. Zore, B. Stromer, R. M. Kasi and C. V. Kumar, Bioconjugate Chem., 2014, 25, 1501-1510.

45 B. Abel and K. Aslan, J. Colloid Interface Sci., 2014, 415, 133142.

46 E. H. Lee, T. Tsujimoto, H. Uyama, M. H. Sung, K. Kim and S. Kuramitsu, Polym. J., 2010, 42, 818-822.

47 Y. Zhang, Y. Yong, J. Ge and Z. Liu, ACS Catal., 2016, 6, 37893795.

48 Q. Menga, Y. Zhanga, X. Jua, C. Maa, H. Maa, J. Chena, P. Zhenga, J. Suna, J. Zhua, Y. Maa, X. Zhaob and T. Chenb, J. Biotechnol., 2016, 226, 8-13.

49 W. Jiang and B. Fang, Sci. Rep., 2016, 6, 30462.

50 Q. Jia, B. Wanga, J. Tanb, L. Zhua and L. Lia, Process Biochem., 2016, 51, 1193-1203.

51 A. Alshammari, M. G. Posner, A. Upadhyay, F. Marken, S. Bagby and A. Ilie, ACS Appl. Mater. Interfaces, 2016, 8, 21077-21088.

52 S. Kale, G. Ulas, J. Song, G. W. Brudvig, W. Furey and F. Jordan, Proc. Natl. Acad. Sci. U. S. A., 2008, 4, 1158-1163.

53 P. A. Santacoloma, G. Sin, K. V. Gernaey and J. M. Woodley, Org. Process Res. Dev., 2011, 15, 203-212.

54 L. Betancor, M. Fernández, K. J. Weissman and P. F. Leadlay, ChemBioChem, 2008, 9, 2962-2966. 